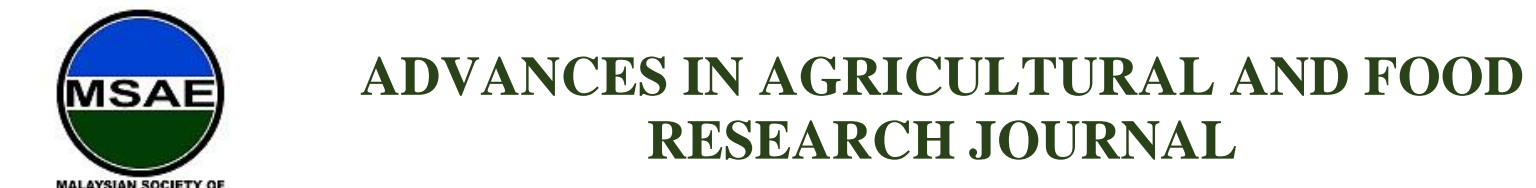

HH PUBLISHER

Original Research Article

\title{
Ergonomic Evaluation of Maize Seeding using Conventional Method and Lightweight Motorized Maize Seeder
}

Hafidha Azmon ${ }^{1 *}$, Mohd Fazly Mail ${ }^{1}$, Mohd Nadzim Nordin ${ }^{1}$, Mohd Shukry Hassan Basri ${ }^{2}$, Norahshekin Abd Rahman, Siti Ashah Ab Rahim ${ }^{1}$

${ }^{1}$ Farm Mechanization Program, Engineering Research Centre, Malaysian Agricultural Research and Development Institute (MARDI), Serdang Selangor, fazlym@mardi.gov.my, mnadzim@mardi.gov.my

${ }^{2}$ Smart and Precision Farming Program, Engineering Research Centre, Malaysian Agricultural Research and Development Institute (MARDI), Serdang Selangor, shukry@ mardi.gov.my

*Corresponding author: Hafidha Azmon, Farm Mechanization Program, Engineering Research Centre, Malaysian Agricultural Research and Development Institute (MARDI), Serdang Selangor, hafidha@mardi.gov.my

\begin{abstract}
Manual activity in maize seeding shows an awkward posture due to repetitive movement on walking forward, body lowering, knee bending, squatting, digging, and seed sowing, which can cause body tiring. These are the symptom of human fatigue or the ergonomic hazard in an agricultural field, leading to Musculoskeletal Disorders (MSD) if done repeatedly and extended for a long time. The paper explained the ergonomic evaluation of seeding risk assessment using two methods; bare hand and lightweight motorized maize seeder. The evaluated maize seeder was designed with a minimum number of parts to make the assembly and maintenance requirements easy without affecting the functionality of the metering device. The maize seeder is easy to operate, light to carry, and convenient to use with a single-handed griper to improve ergonomics in the field. Using the concept of gravitational drop and the battery to power the motor, the farmer experiences a slightly bent body position with a relaxed posture that requires less stressful angles on seeding activity. Seeding postures on methods were evaluated using Rapid Upper Limb Assessment (RULA) and Rapid Entire Body Assessment (REBA) to determine the area of bodily discomfort. The RULA result shows that the ergonomic risk score on manual seeding activity was at score 7, which is high risk compared to seeding activity using the maize seeder, which results in a score of 4 that shows a low risk.In comparison, the REBA result shows a high risk on manual seeding with a score of 11 and a low risk on seeding with a seeder, which is in score 3seeding by bare hand, adopting poor posture at the neck, trunk, and wrist twist. The work rate for seeding maize using the conventional method and seeder was $0.114 \mathrm{~m} / \mathrm{s}$ and $0.167 \mathrm{~m} / \mathrm{s}$, respectively. The study concludes that using the lightweight motorized maize seeder can reduce the risks of MSDs due to working in an awkward posture in sowing maize on the field.
\end{abstract}

Keywords: ergonomic; maize seeder; Rapid Upper Limb Assessment; seeding 
Received: $16^{\text {th }}$ March 2021

Received in revised form: $28^{\text {th }}$ June 2021

Accepted: $30^{\text {th }}$ June 2021

Available Online: $4^{\text {th }}$ July 2021
Citation: Azmon H, Mail MH, Nordin MN, et al. Ergonomic evaluation of maize seeding using conventional method and lightweight motorized maize seeder. Adv Agri Food Res J 2021; 2(2): a0000231. https://doi.org/10.36877/aafrj.a0000231

\section{Introduction}

The cultivation of maize or corn (Zea mays) in Malaysia contributes to the most significant production of industrial crops, at 79,932 tonnes in 2019, compared to 68,907 tonnes in 2018 (Jabatan Pertanian \& Department of Agriculture, 2016). The collective number of small-scale maize plantations makes a solid contribution to Malaysian maize production. Maize has two types; one is a cereal used for animal nutrition, and the other is grown for cob production as fresh human consumption. Sweet corn is one of the varieties of maize with the highest demand for fresh cob apart from other versatile uses of the entire crop. Sweet corn has enormous market potential in Malaysia. There are various varieties of sweet corn cultivated globally. The most highly used in Malaysia were hybrid varieties and openpollinated types such as Mas Madu, Manis Madu, and Thai Supersweet (Ali et al., 2003).

Maize cultivation involves many farm activities: bed preparation, seedling, crop maintenance, irrigation, and cob harvest. Seeding counts as a critical step in maize production since the successful seedling establishment determines the future harvest (Finch-Savage \& Bassel, 2016). In the conventional practice of maize seeding method, the seed is sown manually by farmers. Seeding maize requires a farmer to sow 1 or 2 seeds in each hole along the bed prepared. Conventional activity on seeding is the most inexpensive approach, but it is a laborious and time-consuming operation for high volume open field crop cultivation. Apart from the tedious job, manual seeding in the field leads to tiredness and body injuries to the farmer. Farmer's job is repetitive, arduous, physiologically demanding for a long time, causing farmers to utilize various body parts intensively. This job creates pain in their limbs and other body parts due to adopting various postures throughout the plant cultivating activity (Pal \& Dhara, 2018; Vyas, 2015). Several research studies have studied various aspects of conventional seeding or planting, such as working posture in the field (Granzow et al., 2019; Granzow et al., 2018; Hodges \& Kennedy, 2011). Musculoskeletal disorders (MSD) or injuries experienced on delivering any job are pervasive in manual agricultural activities since they involve repetitive poor posture adopting for extended working hours (WalkerBone \& Palmer, 2002). MSD is related to injuries on muscles, tendons, or nerves that attack workers with poor posture during working on their jobs. Poor work posture in farming is indicated when the farmer repeats the whole activity, which involves body moving, lowering the body, bending, kneeling, squatting, and wrist-twisting that can cause awkward postures and fatigue pain (Nico et al., 2004). MSD was shown to be widespread among farmers, where they experience body pain more commonly when they work in a squatting position (Basher et al., 2015). In the case of maize seeding, the farmer has to carry seeds, dig a hole before 
releasing seed and fill it back with soil to avoid seed taken by pest or animal. These activities contribute to backache, and if prolonged, it can lead to human fatigue and body disability. According to OSHA, the physical stress on the human can be reduced by improving the work environment, enhancing the way of delivering the job, appropriately using tools or equipment to fit the worker to eliminate or reduce the MSDs when working. Special tools are needed to assist farmers in sowing seeds to keep the high performance and production in seeding activity.

The study was related to Work-related MSD problems. The conventional method of maize seeding using bare hands and the new seeding method using the motorized seeder tools are compared in terms of musculoskeletal hazard assessment and time efficiency. The maize seeder used in this study was developed by the Malaysian Agricultural Research and Development Institute (MARDI) to assist farmers in seeding maize in the field (Mail et al., 2014). The data analysis was performed for four operating postures in both methods of seeding that were determined to be potentially high risk to the farmers' bodies.

\section{Materials and Methods}

The study is designed to evaluate the various tasks performed by farmers and the work posture adopted by them while seeding maize using two methods. The methods involve seeding maize using a bare hand and a lightweight motorized maize seeder developed by MARDI. A comparative test is done by evaluating both ways.

\subsection{Operator Selection}

The experimental subject is a male between 40 and 60 years old, under the 50th percentile of Malaysian Malaysian adults, $1.686 \mathrm{~m}$ (Mohamad et al., 2010).

\subsection{Maize Seeding Methods}

\subsubsection{Conventional seeding by using bare hand}

The work postures are collected by taking pictures of the operator while sowing maize seeds. Two types of seeding conditions are evaluated. The test is done by seeding maize using a bare hand in a $100 \mathrm{~m}$ bed with the distance of planting between seeds is $50 \mathrm{~cm}$. The activity of manual seeding involves four posture positions of the farmer: walking, squatting, lowering the body, and standing up. The time is taken for the seeding to complete the whole dedicated maize plot.

\subsubsection{Maize seeding using a lightweight motorized maize seeder}

The lightweight motorized maize seeder was developed and tested in Engineering Research Centre, Malaysian Agricultural Research and Development Institute (MARDI), 
Selangor. The tool was designed for sowing maize seeds in the open field. Creating this lightweight motorized maize seeder aims to develop an easy device to operate, light to carry, and convenient to use with a single-handed griper to improve ergonomics in the field. The size of the seeder is based on the parameter required by the standard size of 95 percentile of operator sizes. The developed maize seeder is shown in Figure 1, and the details are described in Table 1.

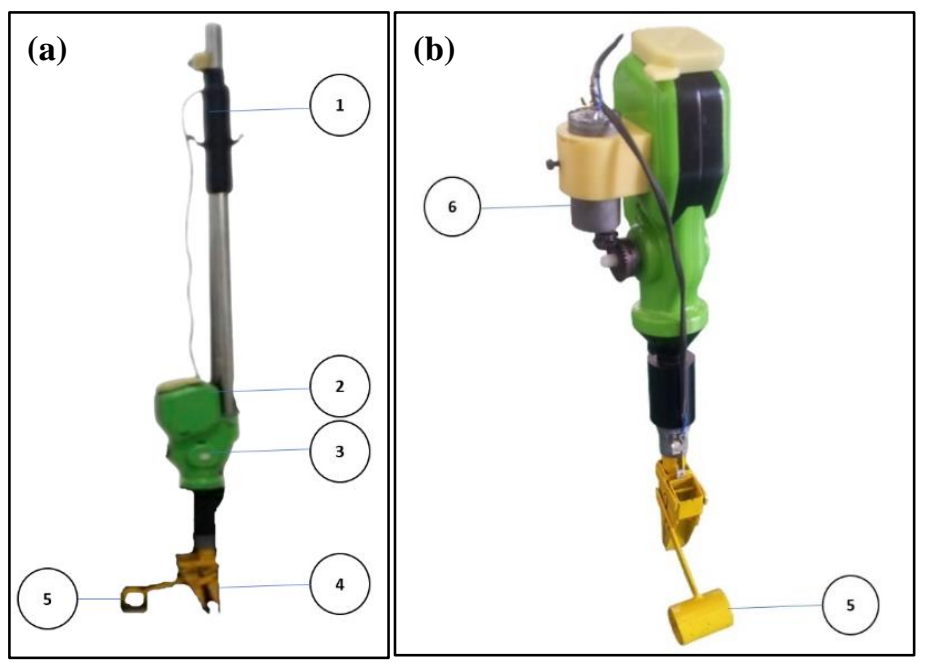

Figure 1. The lightweight motorized maize seeder: (a) front view; (b) close-up view.

Table 1. Parts of the lightweight motorized maize seeder.

\begin{tabular}{cc}
\hline No & Part \\
\hline 1 & Rod \\
2 & Seed container \\
3 & Metering device \\
4 & Soil puncher/jaws \\
5 & Guide \\
6 & DC motor \\
\hline
\end{tabular}

The device was designed with a minimum number of parts to make the assembly and maintenance requirements easy without affecting the functionality of the metering device. The maize seeder consists of a $1.2 \mathrm{~m}$ rod, a $12 \mathrm{~V}$ battery, motor as an actuator, metering device, switch, seed container, and hole puncher cum seed dispenser at the lower end of the seeder. The hole punching mechanism consists of jaws that can penetrate the soil and make room for maize seed placement. Salient specifications of the maize seeder developments are shown in Table 2. 
Table 2. Specifications of a lightweight motorized maize seeder.

\begin{tabular}{cc}
\hline Features & Specifications \\
\hline Weight (prototype) & $1.680 \mathrm{~kg}$ \\
Weight (prototype + battery) & $2.265 \mathrm{~kg}$ \\
Weight (prototype + battery + seed) & $2.590 \mathrm{~kg}$ \\
Battery & $12 \mathrm{~V}, 1.2 \mathrm{~A}$ \\
Length & $120 \mathrm{~cm}$ \\
Seed tank capacity & $325 \mathrm{~g}$ \\
\hline
\end{tabular}

The proposed design took into account the anthropometric data developed for Malaysian adults with mean stature height, $168 \mathrm{~cm}$, five percentile, $157 \mathrm{~cm}$, and 95 percentiles, $180 \mathrm{~cm}$ (Mohamad et al., 2010). The seeder is designed with a $120 \mathrm{~cm}$ length appropriate for sowing seed use in the field. The farmer needs to hold the seeder and operates it on elbow height to reduce body discomfort during seeding activity.

The operator requires to carry the maize seeder along the planting rows in a field. The device is functioning when the battery is connected, and the farmer must punch a hole in the soil to drop the seed. When the puncher pokes the land, a pair of jaws at the end of the rod will open, loosen the soil and create a hole. The opening jaws will automatically switch on the motor, and the metering device starts to sort the seed and drop it into a hole. As the operator pulls the seeder out of the soil, jaws immediately close and enabling site closure covering the seed in the hole. The seeder is optimally suited for the effortless insertion of maize seed. This seeder attests to its time-seeding convenience when planting tens of seeds in an open field with ease and consistency.

The device is battery-operated and able to release 1 or 2 seeds at one punch. The metering device is made of Acrylonitrile Butadiene Styrene (ABS) plastic, while the rod is made from aluminum. The ABS material is selected due to its hardness and lightweight to improve ergonomic in fieldwork.

The seed metering device is designed with a rotating plate consists of 10 slots to sort and place the seed before dropping out into the soil. Every time puncher hits the ground, the rotating plate rotates, bringing the next slot in the downright position to drop seed through the jaws. A metering device enables an operator to drop a precise and measured amount of seeds from a dispenser slot when the control mechanism is engaged. The device can release a single seed of the open-pollinated type while 1 to 2 pieces of seeds will drop into the hole when seeding a hybrid type of seed. The main body is installed with the seed container to store a maximum of $325 \mathrm{~g}$ seed suitable for 300 meter $^{2}$ maize plantation. 
The test is done by seeding maize using a seeder in a $200 \mathrm{~m}$ bed with the distance of planting between seeds is $50 \mathrm{~cm}$. Time is taken to complete the whole task of seeding in the dedicated maize plot.

\subsection{Task Risk Assessment}

Two methods of seeding maize were evaluated using two types of assessment; the Rapid Upper Limb Assessment (RULA) and the Rapid Entire Body Assessment (REBA).

\subsubsection{Rapid upper limb assessment (RULA)}

RULA is a method to estimate the risk in the postural body when delivering jobrelated to upper limb discomfort. The results for risk scores obtained for each component of the risk assessment are recorded. The data processing will result in the scores, risk levels, and the corrective action that should be done. Dr. Alan Hedge developed the RULA worksheet to determine risk factors experienced by workers in the upper limb during delivering their job at a specific time (Gómez-Galán et al., 2020). The RULA consists of three parts of assessment: the determination of posture on several parts of the body, muscle use in the activity, and force exertion on the body while working. The repetitiveness and static posture are also declared in the assessment to calculate the risk assessment score. Table 3 shows the level of MSD risk for each result of RULA scores.

Table 3. The level of MSD risk for each result of RULA scores.

\begin{tabular}{ccc}
\hline Score & Level of MSD Risk & Action \\
\hline $1-2$ & Negligible & Acceptable, no action required \\
$3-4$ & Low & Further investigation, change may be needed \\
$5-6$ & Medium & Further investigation, change required soon \\
$6+$ & High & Implement changes required now \\
\hline
\end{tabular}


Figure 2 shows the RULA worksheet and scores to evaluate employee work risk.

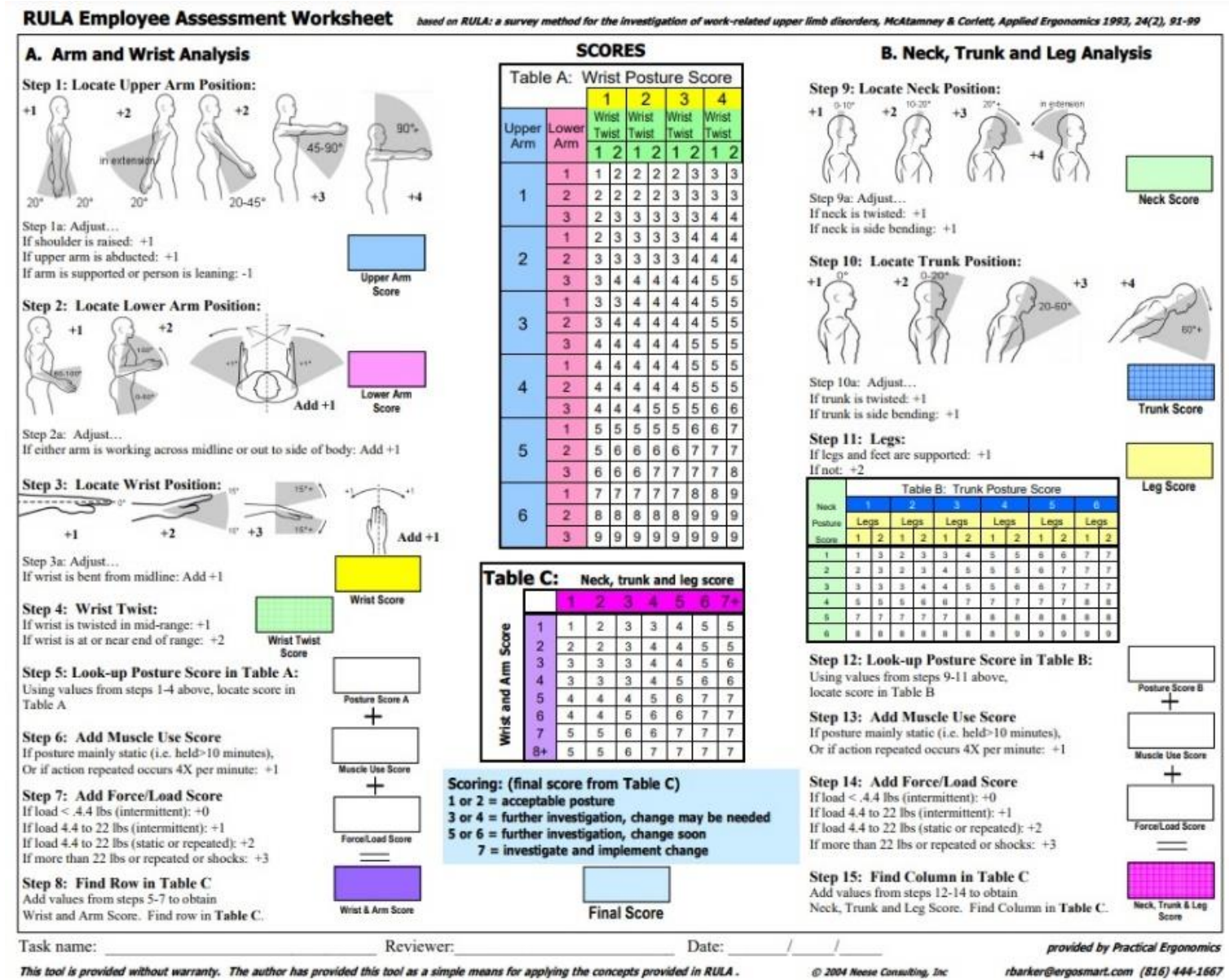

Figure 2. Dr. Alan Hedge designed the RULA worksheet.

\subsubsection{Rapid entire body assessment (REBA)}

REBA is a tool to evaluate MSD for the entire body in extremities where the risk factor on upper and lower parts of the body can rapidly evaluate. The inputs of REBA include the type of body parts movement, force exertions, coupling measurement, and repetition of the action. REBA is an easy tool to describe the posture and the level of risk (Rizkya et al., 2018). The REBA risk assessment is evaluated using the software ErgoPlus. Table 4 shows the level of MSD risk for each result of REBA scores.

Table 4. The level of MSD risk for each result of REBA scores.

\begin{tabular}{ccc}
\hline Score & Level of MSD Risk & Action \\
\hline 1 & Negligible & Acceptable, no action required \\
2 or 3 & Low & change may be needed \\
4 to 7 & Medium & Further investigation, change required soon \\
8 to 10 & High & Investigate and implement changes \\
$11+$ & Very high & Implement changes \\
\hline
\end{tabular}




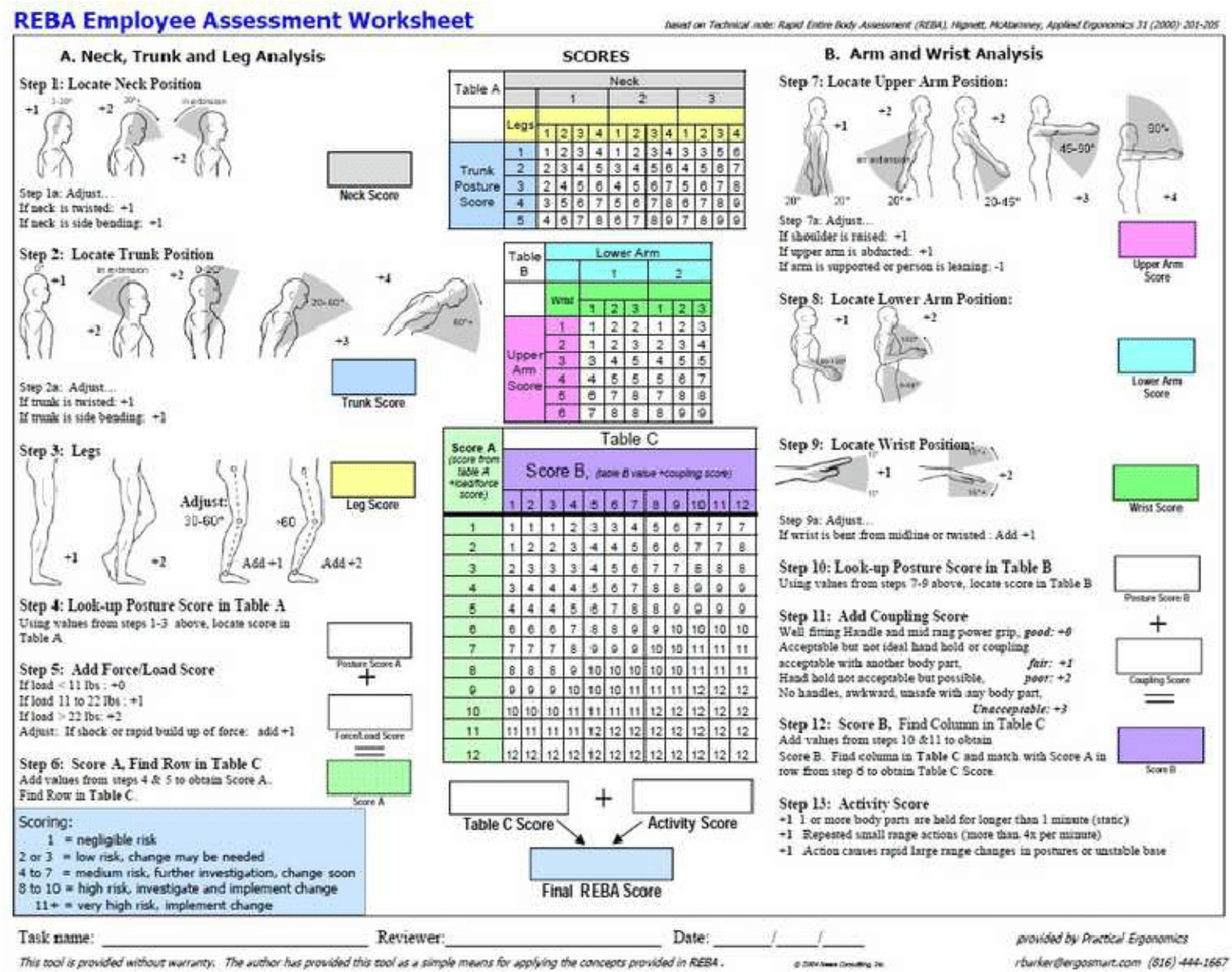

Figure 3. The REBA worksheet was designed by Dr. Sue Hignett and Dr. Lynn McAtamney.

\subsection{Working Posture Evaluation}

The study takes part in a maize plot in Serdang, Selangor. The task started with an observation of maize seeding activity in four prominent body positions. For the conventional method of seeding, postural body observation is captured when a farmer is in the conditions below:

1. Walking forward (Change position from one position to another place)

2. Lowering body from walking into a squat position

3. Seeding operation (hole digging and covering, releasing seed into the soil)

4. Standing up from squatting to move to another place

Assessment of maize seeding using a lightweight motorized maize seeder is evaluated in the stage where the farmer is:

1. Walking forward (Change position from one position to another place)

2. Punching a hole

3. Pushing a maize seeder to release seed into a hole

4. Pulling the maize seeder out from the soil 
All parts of the body are evaluated and scored based on the RULA measurement worksheet.

\section{Results and Discussion}

The data collected from the observation of seeding maize using hand and lightweight motorized maize seeder were analyzed. The work rate for seeding maize using the conventional method and seeder was $0.114 \mathrm{~m} / \mathrm{s}$ and $0.167 \mathrm{~m} / \mathrm{s}$, respectively. There are 200 holes in a $100 \mathrm{~m}$ bed. The time for manually seeding activity is 31 minutes while seeding maize using a motorized seeder consumed shorter than manual seeding. The time taken for seeding maize using a seeder is 17 minutes. For this study, both subjects are male; 44 years old with stature height $1.67 \mathrm{~m}$ for sowing seed using bare hand, and 55 years old $1.70 \mathrm{~m}$ for subject sowing seed using a maize seeder.

\subsection{Maize Seeding Postural Body Assessment Using RULA Method}

\subsubsection{Conventional seeding assessment of RULA method}

The RULA analysis of conventional maize seeding by the farmer is shown in Table 5. Four activities done during manual seeding are identified; walking forward, bending and lowering the body, squatting (for hole digging, seeding, and hole covering), and standing up from squatting. The observation clearly showed that an hour's activity on seeding contributes to awkward postures experience to the farmer. Based on the result, five body parts create discomfort for the farmer when seeding maize using traditional methods such as the neck, trunk, arm, wrist, and leg. Figure $4-6$ shows the postural body of a farmer using a bare hand in the conventional method of maize seedling.

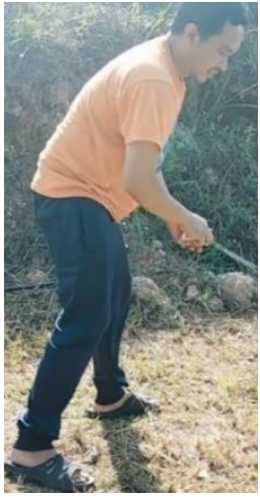

(a)

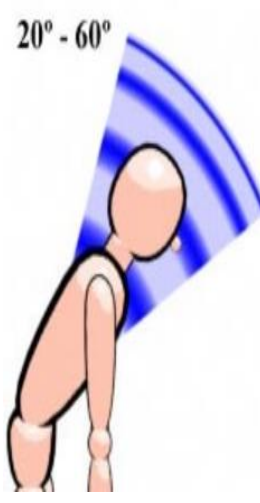

(b)

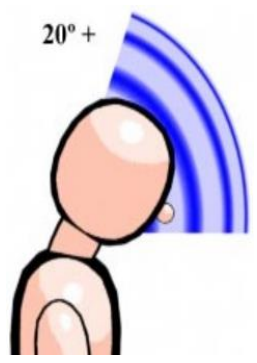

(c)

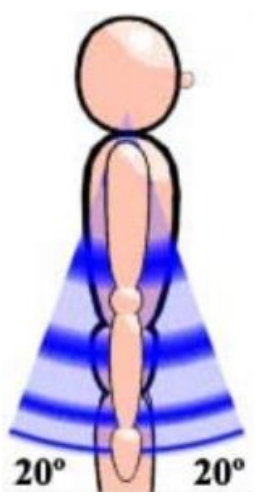

(d)

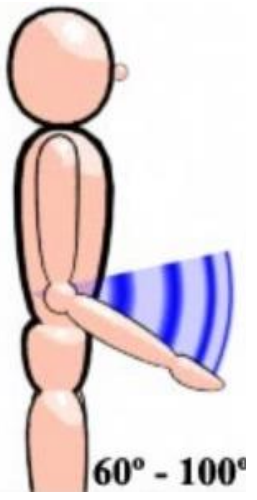

(e)

Figure 4. Awkward working posture while walking forward (a) farmer is walking with back flexion (b) trunk posture (c) neck posture (d) upper arm posture (e) lower arm posture. 


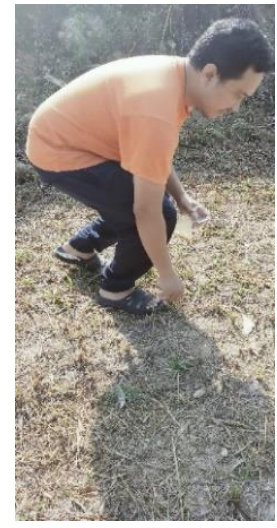

(a)

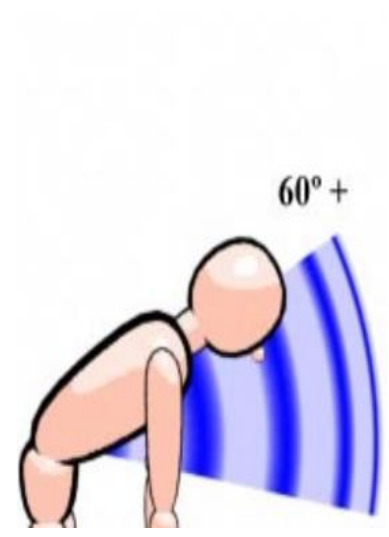

(b)

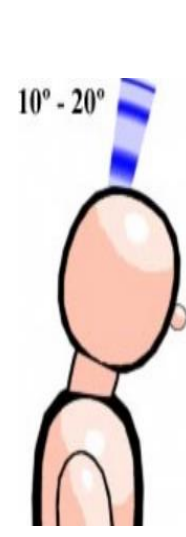

(c)

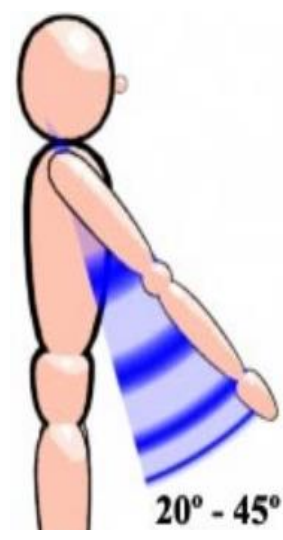

(d)

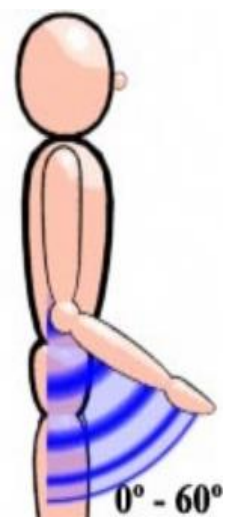

(e)

Figure 5. Awkward working posture while lowering the body to squat and standing up from squatting (a) farmer is going to squat (b) trunk posture (c) neck posture (d) upper arm posture (e) lower arm posture.

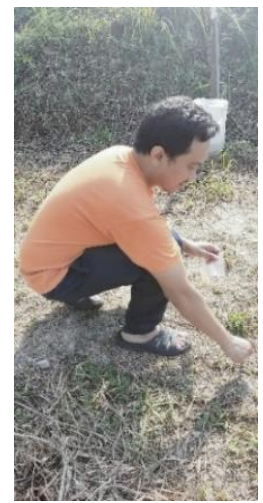

(a)

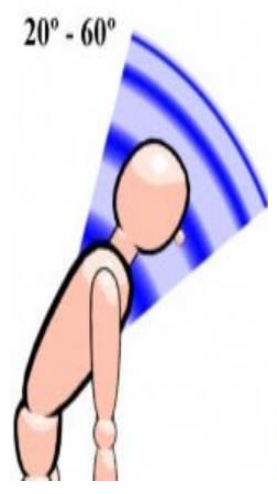

(b)

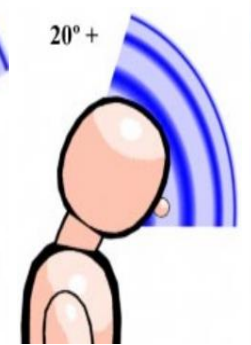

(c)

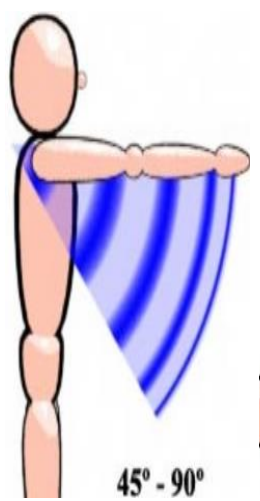

(d)

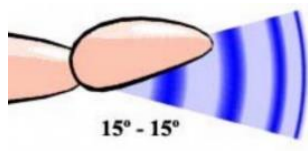

(e)

Figure 6. Awkward working posture while digging a hole, seeding and covering the hole (a) farmer is in squat position (b) trunk posture (c) neck posture (d) upper arm posture (e) wrist posture.

Table 5 shows the RULA score for farmer assessment results for activities involves in seeding. The score and calculation of posture A, posture B, wrist \& arm and neck, trunk \& leg refer to the RULA worksheet developed by Dr. Alan Hedge.

Table 5. RULA Farmer assessment result for awkward working posture during maize seedling.

\begin{tabular}{ccccc}
\hline Score / Activity & $\begin{array}{c}\text { Walking } \\
\text { forward }\end{array}$ & $\begin{array}{c}\text { Lowering body to } \\
\text { squat }\end{array}$ & $\begin{array}{c}\text { Hole digging and } \\
\text { covering/ seeding }\end{array}$ & $\begin{array}{c}\text { Standing up from } \\
\text { the squat }\end{array}$ \\
\hline Upper arm & 1 & 2 & 3 & 2 \\
Lower arm & 1 & 2 & 1 & 2 \\
Wrist & 2 & 2 & 2 & 2 \\
Wrist twist & 1 & 1 & 2 & 1 \\
Posture A & 2 & 3 & 7 & 3 \\
Muscle use & 1 & 1 & 1 & 1 \\
\hline
\end{tabular}




\begin{tabular}{|c|c|c|c|c|}
\hline Score / Activity & $\begin{array}{l}\text { Walking } \\
\text { forward }\end{array}$ & $\begin{array}{c}\text { Lowering body to } \\
\text { squat }\end{array}$ & $\begin{array}{l}\text { Hole digging and } \\
\text { covering/ seeding }\end{array}$ & $\begin{array}{c}\text { Standing up from } \\
\text { the squat }\end{array}$ \\
\hline Force Load & 2 & 2 & 2 & 2 \\
\hline Wrist \& Arm & 5 & 6 & 7 & 6 \\
\hline Neck & 3 & 2 & 3 & 2 \\
\hline Trunk & 3 & 4 & 3 & 4 \\
\hline Legs & 1 & 1 & 1 & 1 \\
\hline Posture B & 4 & 5 & 4 & 5 \\
\hline Muscle use & 1 & 1 & 1 & 1 \\
\hline Force Load & 0 & 0 & 0 & 1 \\
\hline $\begin{array}{c}\text { Neck, trunk \& } \\
\text { leg }\end{array}$ & 5 & 6 & 5 & 6 \\
\hline RULA & 6 & 7 & 7 & 7 \\
\hline Risk level & Medium & High & High & High \\
\hline Action & $\begin{array}{c}\text { Further } \\
\text { investigation, } \\
\text { change required } \\
\text { soon }\end{array}$ & $\begin{array}{l}\text { Implement changes } \\
\text { required now }\end{array}$ & $\begin{array}{l}\text { Implement changes } \\
\text { required now }\end{array}$ & $\begin{array}{l}\text { Implement changes } \\
\text { required now }\end{array}$ \\
\hline
\end{tabular}

\subsubsection{Maize seeding assessment using a lightweight motorized seeder by RULA method}

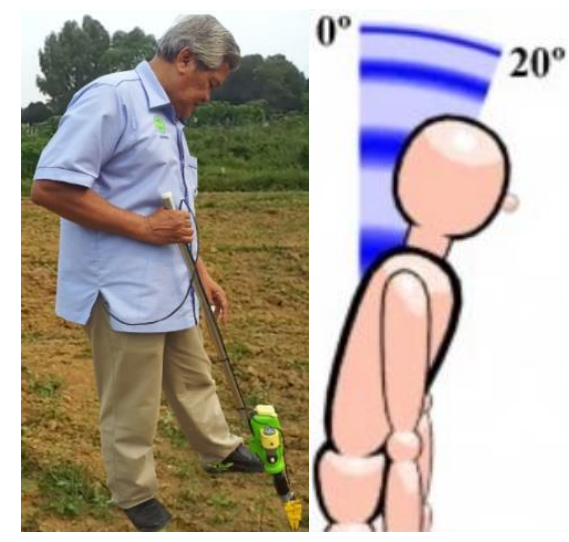

(a)

(b)

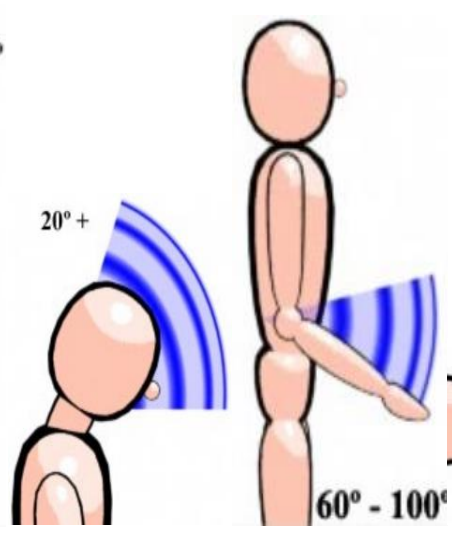

(c)

(d)

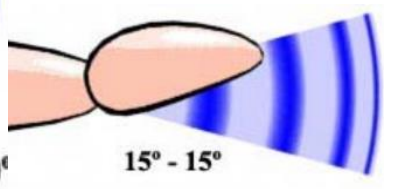

(e)

Figure 7. Awkward working posture while punching a hole using the seeder (a) farmer is pushing seeder vertically (b) trunk posture (c) neck posture (d) lower arm posture (e) wrist. 


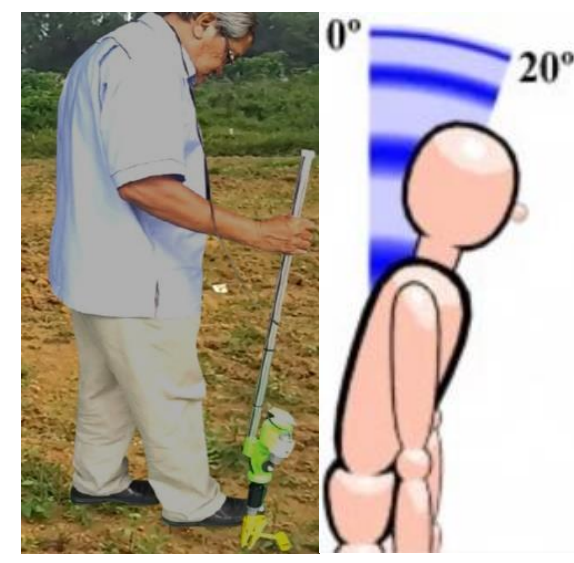

(a)

(b)

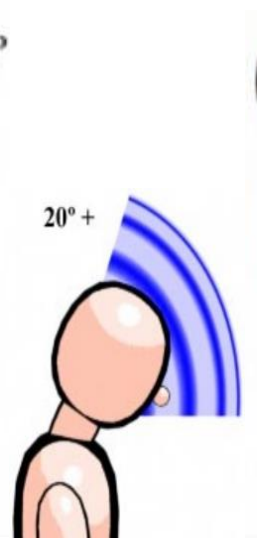

(c)

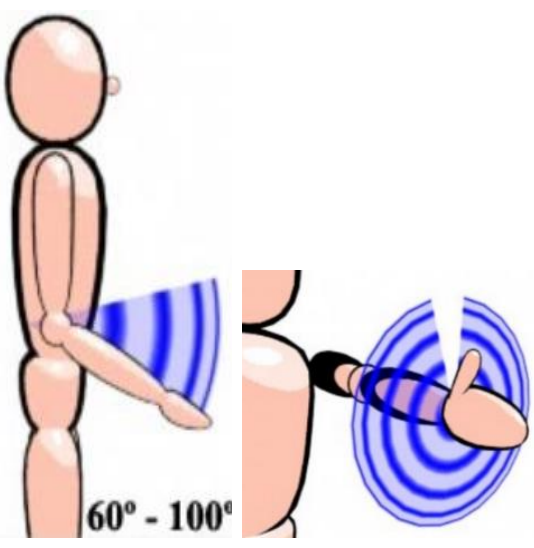

(e)

Figure 8. Awkward working posture while releasing seed using the seeder (a) farmer is pushing seeder horizontally (b) trunk posture (c) neck posture (d) lower arm posture (e) wrist twist.

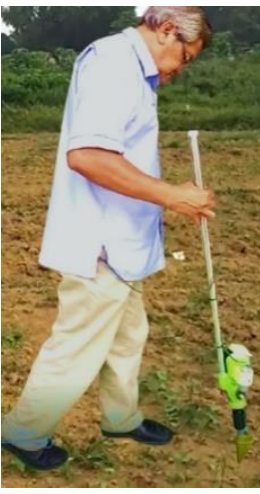

(a)

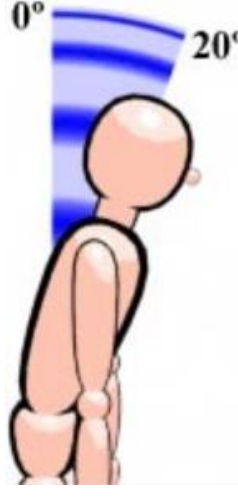

(b)

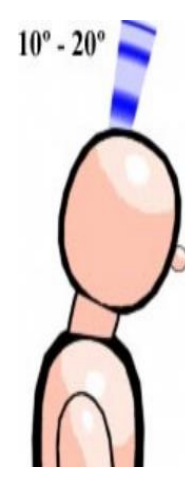

(c)

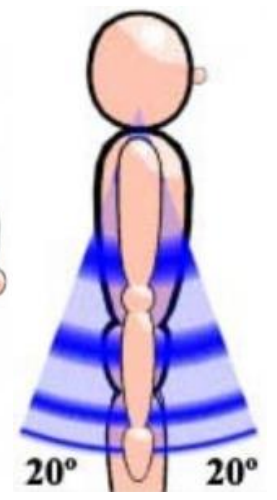

(d)

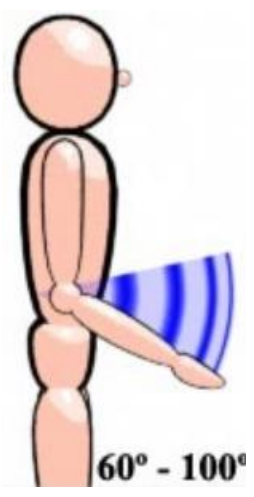

(e)

Figure 9. Awkward working posture while closing a hole using the seeder (a) farmer is pulling the seeder out from the soil (b) trunk posture (c) neck posture (d) upper arm posture (e) lower arm posture.

Table 6. RULA Farmer assessment results for awkward working posture while seeding maize using a lightweight motorized maize seeder.

\begin{tabular}{ccccc}
\hline Score / Activity & Walking forward & $\begin{array}{c}\text { Punching hole } \\
\text { (Pushing seeder } \\
\text { vertically) }\end{array}$ & $\begin{array}{c}\text { Seeding (Pushing } \\
\text { seeder horizontally } \\
\text { to release seed) }\end{array}$ & $\begin{array}{c}\text { Pulling seeder } \\
\text { (Releasing } \\
\text { seeder) }\end{array}$ \\
\hline Upper arm & 1 & 1 & 1 & 1 \\
Lower arm & 1 & 1 & 1 & 1 \\
Wrist & 2 & 2 & 2 & 2 \\
Wrist twist & 1 & 1 & 2 & 2 \\
Posture A & 2 & 2 & 2 & 2 \\
Muscle use & 1 & 1 & 1 & 1 \\
Force Load & 2 & 2 & 2 & 2 \\
Wrist \& Arm & 5 & 5 & 5 & 5
\end{tabular}




\begin{tabular}{ccccc}
\hline Score / Activity & Walking forward & $\begin{array}{c}\text { Punching hole } \\
\text { (Pushing seeder } \\
\text { vertically) }\end{array}$ & $\begin{array}{c}\text { Seeding (Pushing } \\
\text { seeder horizontally } \\
\text { to release seed) }\end{array}$ & $\begin{array}{c}\text { Pulling seeder } \\
\text { (Releasing } \\
\text { seeder) }\end{array}$ \\
\hline Neck & 2 & 3 & 3 & 2 \\
Trunk & 2 & 2 & 2 & 2 \\
Legs & 1 & 1 & 1 & 1 \\
Posture B & 2 & 3 & 3 & 2 \\
Muscle use & 1 & 1 & 1 & 1 \\
Force Load & 0 & 1 & 0 & 0 \\
Neck, trunk \& leg & 3 & 5 & 4 & 3 \\
RULA & 4 & 6 & 5 & 4 \\
Risk level & Low & Medium & Medium & Low \\
Action & $\begin{array}{c}\text { Further } \\
\text { investigation, } \\
\text { change may be } \\
\text { needed }\end{array}$ & $\begin{array}{c}\text { Further } \\
\text { investigation, } \\
\text { change required }\end{array}$ & $\begin{array}{c}\text { Further } \\
\text { investigation, } \\
\text { change required }\end{array}$ & $\begin{array}{c}\text { Further } \\
\text { investigation, } \\
\text { change may be } \\
\text { needed }\end{array}$ \\
\hline
\end{tabular}

3.2 Maize Seeding Postural Body Assessment Using REBA Method

3.2.1 Conventional seeding and seeding using lightweight maize seeder assessment by REBA method

The REBA risk assessment evaluated using ErgoPlus software is shown in Figure 10.
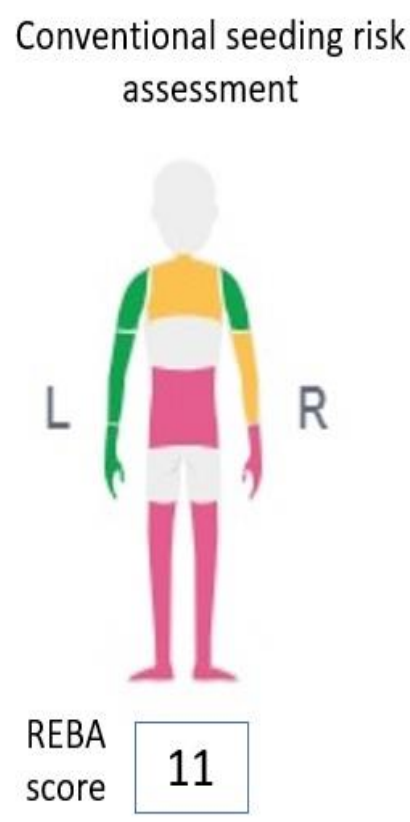

Maize seeding using

lightweight motorized seeder

risk assessment

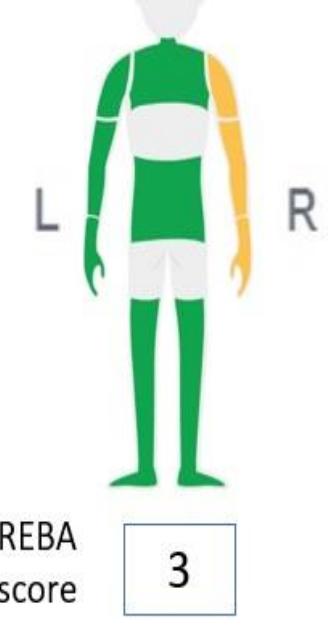

Figure 10. Awkward working posture while seeding maize in the field risk assessment using REBA. 


\section{Discussions}

The study shows that conventional seeding is a high risk to the musculoskeletal health of farmers. Two observational ergonomic risk assessments, RULA and REBA, show that manual seeding in the field has a high degree risk of MSD, with some varied results between RULA and REBA score reflecting the focus of each body part and measurement of risk assessment. Both subjects have slightly the same height have different body postures on delivering tasks for two seeding methods. Operators with five percentile and 95 percentile stature height may have different body postures when dealing with maize seeders. Working with repeated standing and squatting at the field is considered a bad posture for the human being. Manual activity in maize seeding adopting movement, lowering the body, knee bending, digging, and seed sowing can cause awkward postures due to heavy exertion on the body. From Figure 10, REBA analysis on manual seeding highly affects the trunk, leg, and wrist muscle. Excessive leg and trunk use are vital to stand and squat to sow seed into the soil. Due to this activity, farmers experience body discomfort and tiredness due to prolonged awkward posture and rapid movement changes with high repetitions of the tasks. The farmer's wrist also obviously shows a high risk of MSD due to the parts used to dig, sow seeds, and compact soil to complete the seeding activity. The farmer also experiences neck and lower arm discomfort due to repetitive use of these body parts to bend and allow the sowing process to be done.

Compared to the result of seeding maize using a lightweight motorized maize seeder, the evaluation of risk assessment shows that this device can reduce the MSDs of the farmer. From the REBA analysis shows in Figure 10, the use of the seeder only affects the muscle on the arms and wrist. This is due to the use of light force to push and pull the seeder into and out from the soil to release seeds. The other parts of the body show no harm in adopting the seeder while seeding. Using the concept of gravitational drop and the battery to power the motor, the farmer experiences a slightly bent body position with a relaxed posture that requires less stressful angles on seeding activity.

Based on the risk assessment result, it is proposed to seed maize using the motorized maize seeder. Using this device, the operator's posture can be more upright and no longer bent and position the trunk in a neutral region. The maize seeder is easy to use, requiring a bit of manual pressure to create a hole. The seeder is powered by a battery and suitable for multiple plantings were squatting and kneeling while seeding can be avoided. This device makes maize planting easier and consistent than a conventional bare hand of digging and is optimally suited for the effortless insertion of maize seed. As all know, farmer for small-scale cultivation primarily refers to older adults. They will highly require a device to assist them in seeding as it will enable them to dig holes and drop a seed without having to kneel and bend over their body. Thus, the lightweight motorized maize seeder is suitable and recommended to be used in the field for small-scale maize cultivation. 


\section{Conclusions}

This research concludes that the lightweight motorized maize seeder is capable of reducing the MSD risk on farmers. The farmer is particularly at high risk of getting backache and lower limb pain while seeding maize using bare hands without tool assistance. The REBA and RULA score assessment results are displayed in detail for each body limb segment in real-time. The use of lightweight motorized maize seeds in replacing the bare hand reduces the ergonomic risk in seeding maize activities from the original REBA score 11. The RULA score is seven, down to the REBA score three RULA score of 4.

Conflicts of Interest: The authors declare no conflict of interest.

\section{References}

Ali, E., Saleh, G., Wahab, Z., et al. (2003). Performance, heritability, and correlation studies on varieties and population cross of sweet corn. Asian Journal of Plant Sciences, 2(10), 756-760. https://doi.org/10.3923/ajps.2003.756.760

Basher, A., Nath, P., Siddique, Z., et al. (2015). Musculoskeletal disorder (MSD) among agricultural workers. Mymensingh Medical Journal: MMJ, 24(1), 1-8.

Finch-Savage, W. E., \& Bassel, G. W. (2016). Seed vigour and crop establishment: extending performance beyond adaptation. Journal of Experimental Botany, 67(3), 567-591. https://doi.org/10.1093/jxb/erv490

Gómez-Galán, M., Callejón-Ferre, Á.-J., Pérez-Alonso, J., et al. (2020). Musculoskeletal risks: RULA bibliometric review. International Journal of Environmental Research and Public Health, 17(12), 4354. https://doi.org/10.3390/ijerph17124354

Granzow, R. F., Schall, M. C., Smidt, M. F., et al. (2018). Characterizing exposure to physical risk factors among reforestation hand planters in the Southeastern United States. Applied Ergonomics, 66, 1-8. https://doi.org/10.1016/j.apergo.2017.07.013

Granzow, R., Schall, M. C., Smidt, M., et al. (2019). Measuring the effect of tool design on exposure to physical risk factors among novice hand planters. Proceedings of the Human Factors and Ergonomics Society Annual Meeting, 63(1), 1013-1017. https://doi.org/10.1177/1071181319631091

Hodges, A. N. H., \& Kennedy, M. D. (2011). Physical exertion and working efficiency of reforestation workers. Journal of Occupational Medicine and Toxicology, 6(20), 1-7 https://doi.org/10.1186/1745-6673-620

Jabatan Pertanian, \& Department of Agriculture. (2016). Keluasan bertanam dan pengeluaran sayur-sayuran utama mengikut jenis, 2017-2019. Statistik Tanaman ( Sub-Sektor Tanaman Makanan ) 2019, 1-102. http://www.doa.gov.my/index/resources/aktiviti_sumber/sumber_awam/maklumat_pertanian/perang kaan_tanaman/booklet_statistik_tanaman_2019.pdf\%0Awww.moa.gov.my/web/guest/dasaragromakanan-negara-2011-2020-dan

Pal, A., \& Dhara, P. C. (2018). Work related musculoskeletal disorders and postural stress of the women cultivators engaged in uprooting job of rice cultivation. Indian Journal of Occupational and Environmental Medicine, 22(3), 163-169. https://doi.org/10.4103/ijoem.IJOEM_104_18

Mail, M. F., Mohd Nadzim N., Md. Akhir H., et al. (2014). Design requirement study for semi-automated handheld maize seeder. National Conference on Agricultural and Food Mechanization 2014 (NCAFM 2014), 128-140. 
Mohamad, D., Deros, B., Ismail, A. R., et al. (2010). Development of a malaysian anthropometric database. World Engineering Congress 2010, Conference on Manufacturing Technology and Management, August.

Nico J. D., Christine M. H., \& Don, B. C. (2004). Working Postures and Movements (1st ed.). CRC Press.

Rizkya, I., Syahputri, K., Sari, R. M., et al. (2018). Evaluation of work posture and quantification of fatigue by Rapid Entire Body Assessment (REBA). IOP Conference Series: Materials Science and Engineering, 309(1), 1-6. https://doi.org/10.1088/1757-899X/309/1/012051

Vyas, R. (2015). Ergonomic assessment of prevalence of musculoskeletal disorders among indian agricultural workers. Journal of Ergonomics, S4(005), 1-4. https://doi.org/10.4172/2165-7556.s4-005

Walker-Bone, K., \& Palmer, K. T. (2002). Musculoskeletal disorders in farmers and farm workers. Occupational Medicine (Oxford, England), 52(8), 441-450. https://doi.org/10.1093/occmed/52.8.441 